\title{
Recurrent Fulminant Myocarditis Accompanied by Lymphoid Follicle Formation in Myocardium
}

\author{
Takashi Omatsu ${ }^{1}$, Takaharu Hayashi ${ }^{1}$, Yasuhiro Ichibori ${ }^{1}$, Nobuhiko Makino ${ }^{1}$, Akio Hirata ${ }^{1}$, \\ Yoshio Yasumura ${ }^{2}$, Atsushi Hirayama ${ }^{1}$ and Yoshiharu Higuchi ${ }^{1}$
}

\begin{abstract}
:
A 76-year-old man developed repeated fulminant myocarditis in a short period, and immunosuppressive therapy was remarkably effective. A pathologic evaluation showed that inflammatory cells had infiltrated the myocardium. Not only invasion of inflammatory cells but also the formation of lymphoid follicle was noted. Chronic myocardial inflammation was proven, but cardiac sarcoidosis was negative according to the results of various examinations. This is the first report of recurrent autoimmune myocarditis with a lymphoid follicle in the myocardium. These findings may suggest a novel pathogenesis of myocarditis.
\end{abstract}

Key words: myocarditis, recurrence, ectopic lymphoid follicles, immunosuppressive therapy

(Intern Med 59: 3045-3049, 2020)

(DOI: 10.2169/internalmedicine.5268-20)

\section{Introduction}

In most cases, the etiology of myocarditis is unknown. Myocarditis can result from a wide spectrum of infectious pathogens, including viruses, bacteria, chlamydia, rickettsia, fungi, and protozoans, as well as toxic and hypersensitivity reactions (1). In Europe and North America infection with enteroviruses is thought to be the leading cause of disease, especially infection with coxsackievirus B3 (2). Noninfectious causes of myocarditis are alcohol, radiation, chemicals (hydrocarbons and arsenic), and drugs, including doxorubicin and immune checkpoint inhibitor (3).

Acute necrotizing eosinophilic myocarditis and giant-cell myocarditis are two rare idiopathic disorders that share histological features of extensive myocyte necrosis, little fibrosis in the acute phase, and eosinophil-rich infiltrates. These histological myocarditis entities are known to have a good therapeutic response to immunosuppressive agents (4).

We herein report a case of autoimmune myocarditis that did not have evidence of cardiac sarcoidosis, giant-cell myocarditis, or eosinophilic myocarditis and was accompanied by the formation of lymphoid follicles in the myocardium.

\section{Case Report}

A 76-year-old man was transported to our hospital with chief complaints of general fatigue. Echocardiography revealed a markedly impaired ventricular function. The troponin-T levels were elevated at $1.80 \mathrm{ng} / \mathrm{mL}$, and his serum auto-immune antibody was negative (Table 1). His symptoms gradually worsened, and the hourly urine volume decreased despite the intravenous administration of dobutamine at $2.0 \mathrm{~g}$ and milrinone at $0.25 \mathrm{~g}$, reaching $<10 \mathrm{~mL} / \mathrm{h}$. Coronary angiography revealed that his coronary artery was intact (Supplementary material 1). We therefore inserted an intra-aortic balloon pump (IABP) to support his circulation. After insertion of the IABP, the left ventricular ejection fraction gradually recovered, and on day 7 , he was successfully weaned off of the IABP. On day 24, he was discharged with New York Heart Association (NYHA) I (Fig. 1A).

Two months after discharge, he was re-admitted with a chief complaint of general fatigue. On admission, his body temperature was $36.2{ }^{\circ} \mathrm{C}$, pulse rate was $80 \mathrm{bpm}$, and blood pressure was $69 / 57 \mathrm{mmHg}$. His troponin- $\mathrm{T}$ and creatine kinase (CK) levels were elevated at $2.79 \mathrm{ng} / \mathrm{mL}$ and $318 \mathrm{U} /$ $\mathrm{L}$, respectively (Table 2), and an electrocardiogram (ECG) showed double-bundle block accompanied by complete

${ }^{1}$ Osaka Police Hospital, Japan and ${ }^{2}$ Amagasaki Chuo Hospital, Japan

Received: May 7, 2020; Accepted: June 11, 2020; Advance Publication by J-STAGE: August 4, 2020

Correspondence to Dr. Takaharu Hayashi, takaharu0866@yahoo.co.jp 
Table 1. Laboratory Findings during the Patient's Clinical Course.

\begin{tabular}{lcccc}
\hline & First admission & Second admission & Before second discharge & Third admission \\
\hline WBC $(/ \mathrm{mL})$ & 7,200 & 7,700 & 10,200 & 9,400 \\
Eosinophil $(/ \mathrm{mL})$ & 1.5 & 0.9 & 0.4 & 0.3 \\
$\mathrm{RBC}\left(\times 10^{9} / \mathrm{mL}\right)$ & 3.4 & 4.2 & 4.7 & 4 \\
$\mathrm{Hb}(\mathrm{g} / \mathrm{dL})$ & 10.5 & 12.5 & 15.0 & 13.3 \\
$\mathrm{Ht}(\%)$ & 32.3 & 39.7 & 43.3 & 41.3 \\
platelets $\left(\times 10^{4} / \mathrm{mL}\right)$ & 10.6 & 11.7 & 15.5 & 9.8 \\
CK $(\mathrm{U} / \mathrm{L})$ & 196 & 318 & 19 & 150 \\
CK-MB $(\mathrm{U} / \mathrm{L})$ & 24 & 57 & 9 & 28 \\
AST $(\mathrm{U} / \mathrm{L})$ & 152 & 83 & 23 & 56 \\
ALT $(\mathrm{U} / \mathrm{L})$ & 199 & 28 & 40 & 49 \\
LDH (U/L) & 626 & 452 & 279 & 350 \\
BUN (mg/dL) & 20 & 16.1 & 17.5 & 21.7 \\
Cr $(\mathrm{mg} / \mathrm{dL})$ & 0.69 & 0.96 & 0.80 & 0.85 \\
CRP $(\mathrm{mg} / \mathrm{dL})$ & 4.13 & 4.94 & 0.01 & 5.32 \\
NT-pro BNP $(\mathrm{pg} / \mathrm{mL})$ & 14,960 & 14,608 & 1,346 & 8,425 \\
Troponin T (ng/mL) & 1.8 & 2.79 & 0.024 & 1.56 \\
ACE (U/L) & & & & 2.1 \\
sIL-2R (U/L) & & & & 359 \\
Anit-nuclear antibody & negative & & negative \\
\hline
\end{tabular}

CK: creatine kinase, AST: aspartate aminotransferase, ALT: alanine aminotransferase, LDH: lactate dehydrogenase, BUN: blood urea nitrogen, CRP: C-reactive protein, BNP: brain-type natriuretic peptide, IL: interleukin, ACE: angiotensin-converting enzyme

right-bundle branch block and left axis deviation (Fig. 2). Echocardiography revealed the marked reduction in the function of both ventricles again. He soon slipped into cardiogenic shock accompanied by complete atrioventricular (AV) block.

We performed a myocardial biopsy, supported by an IABP, temporary pacemaker and intravenous administration of an inotropic agent. A pathologic evaluation showed that inflammatory cells had infiltrated the myocardium. Biopsy specimens revealed acute lymphocytic myocarditis, showing not only invasion of inflammatory cells but also the formation of fibrosis. In addition, a lymphoid follicle was observed (Fig. 3).

Based on these findings, we immediately administered a high dose $(1,000 \mathrm{mg} /$ day $)$ of intravenous glucocorticoid for 3 days. After the first high-dose steroid administration, his atrioventricular conduction recovered, and his mixed venous oxygen saturation gradually began to rise. On day 4 , he was successfully weaned off of the IABP. Gallium scintillation revealed no accumulation of nuclide in the myocardium ( $\mathrm{S}$. 2). Following steroid pulse treatment, he received oral administration of $50 \mathrm{mg}$ prednisolone daily, which was slowly tapered by $10 \mathrm{mg} /$ week to $30 \mathrm{mg}$ and then reduced by 5 $\mathrm{mg} /$ week. Finally, on day 35 , he was discharged while receiving $15 \mathrm{mg}$ of prednisolone per day (Fig. 1B).

His oral prednisolone dose was gradually decreased by 5 mg every 3 months. Eight months after discharge, he was admitted to our hospital again, taking $5 \mathrm{mg}$ of prednisolone a day. Echocardiography revealed the marked reduction in the function of both ventricles again, and his serum troponin- $\mathrm{T}$ and $\mathrm{CK}$ were re-elevated. After admission, he was treated with intravenous administration of inotropic agents for a few days, but his symptom gradually worsened. On day 3, an IABP was inserted again to support his circulation, and steroid pulse therapy was restarted. He received a high dose $(1,000 \mathrm{mg} /$ day $)$ of intravenous glucocorticoid for 3 days. Neither high serum soluble interleukin-2 receptor nor angiotensin-converting enzyme levels were increased (Table 1). On day 9, he was successfully withdrawn from the IABP, and on day 42, he was weaned from inotropic agents. Finally, on day 70 , he was discharged our hospital taking $30 \mathrm{mg}$ of prednisolone a day (Fig. 1C).

\section{Discussion}

Myocarditis is defined as inflammation of the cardiac muscle that is related to infection, cardiotoxic substances, or autoimmune reactions (5). According to the widely used "Dallas" criteria published in 1987, a diagnosis of active myocarditis requires the presence of inflammatory infiltrates of non-ischemic origin in myocardial tissue associated with necrosis and/or degeneration of adjacent cardiomyocytes (6). In our case, biopsy specimens revealed abnormal infiltrates of lymphocytes and monocytes in the myocardium that met the diagnosis criteria. However, we cannot conclusively diagnose all of these events as myocarditis because we performed a myocardial biopsy only once.

Reflecting on the hospitalization progress, he presented to our hospital with a complaint of general fatigue accompanied by leakage of cardiac troponin-T, ultimately leading to cardiogenic shock. This implies that every presentation was caused by the same event. Limited evidence is available 

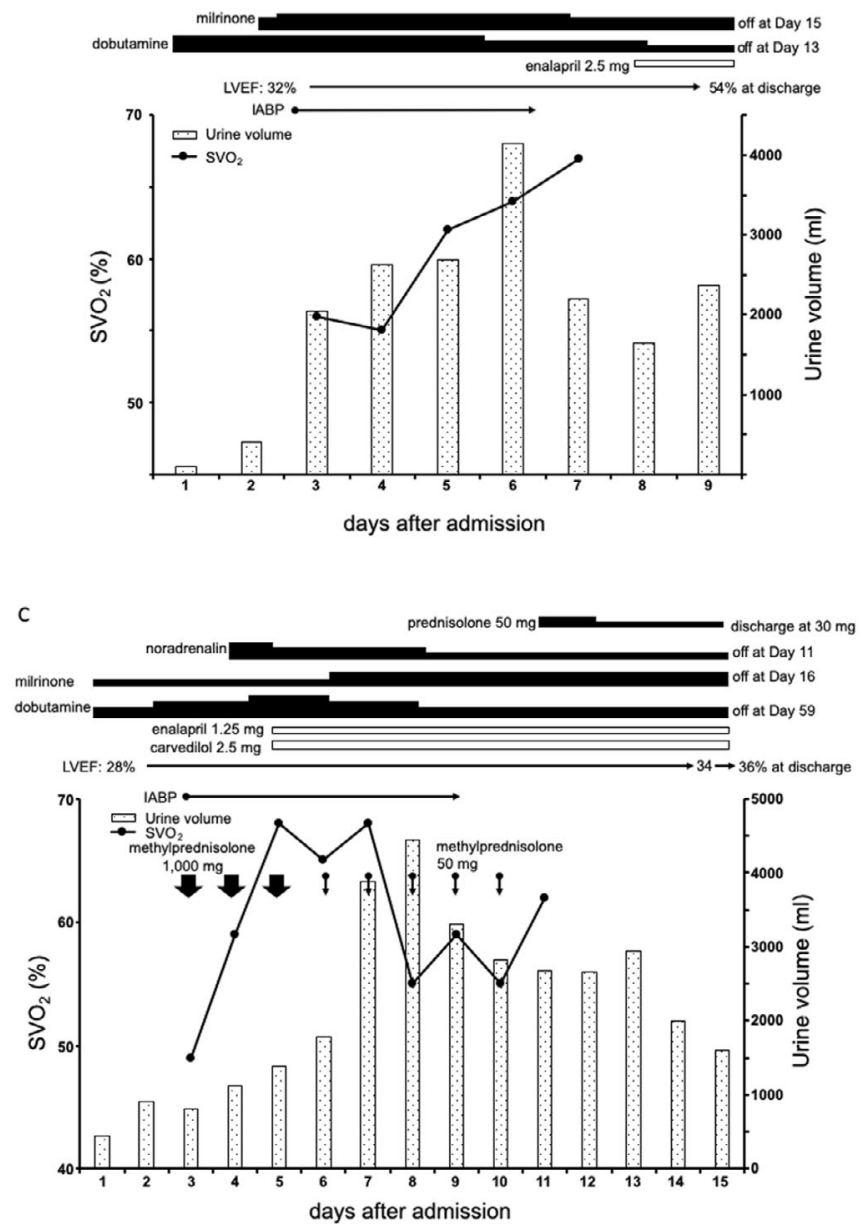

B

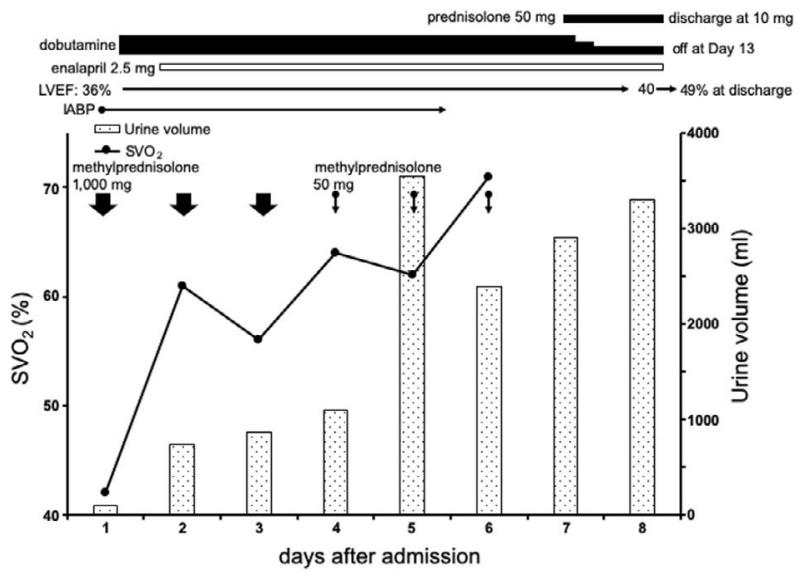

Figure 1. (A, B, C): Clinical course of the patient at each admission. The left vertical axis shows mixed venous oxygen saturation $\left(\mathrm{SVO}_{2}\right)$, and the bar graph shows the total urine volume per day. A: Dobutamine was administered starting at $2 \mathrm{~g}$ and gradually reduced with improvement in the hemodynamics. On day 2 , the intravenous administration of milrinone was started at $0.15 \mathrm{~g}$ and increased to $0.2 \mathrm{~g}$ before being gradually reduced. The left ventricular ejection fraction (LVEF) was decreased at $32 \%$ and then recovered to $54 \%$ at discharge. B: On admission, a myocardial biopsy was performed, supported by an IABP and temporary pacemaker. The intravenous administration of dobutamine was started from $3 \mathrm{~g}$. On day 2 , the oral administration of enalapril was started at $2.5 \mathrm{mg}$. C: Dobutamine and milrinone were started from $2 \mathrm{~g}$ and $0.15 \mathrm{~g}$, respectively. Dobutamine was gradually increased to $5 \mathrm{~g}$, and on day 4, noradrenaline was started from $0.1 \mathrm{~g}$ against prolonged hypotension despite IABP support.

Table 2. Summary of the Patient's Clinical Course from the First Admission to the Final Discharge.

\begin{tabular}{ll}
\hline \multicolumn{1}{c}{ Time } & \begin{tabular}{l} 
Events \\
Hunction was remarkably reduced. Intra aortic balloon pumping (IABP) was inserted to support his circulation. \\
\hline 1st admission
\end{tabular} \\
$\begin{array}{l}\text { 2nd admission } \\
\text { (two months after discharge) }\end{array}$ & $\begin{array}{l}\text { He came to our hospital again because of general fatigue. He became complete AV block and soon fall into } \\
\text { shock vital. He was treated by intravenous administration of high dose of methyl prednisolone. At this }\end{array}$ \\
$\begin{array}{l}\text { 3rd admission } \\
\text { (eight months after discharge) }\end{array}$ & $\begin{array}{l}\text { Unfortunately, his myocarditis had recurred. He could be recovered again owing to IABP and methyl } \\
\text { prednisolone. }\end{array}$ \\
\hline
\end{tabular}

concerning recurrence of myocarditis to guide patient management, as reports on this event are extremely rare (7). We should rule out cardiac sarcoidosis in cases of chronic myocarditis. A clinical examination revealed no lung or ocular 


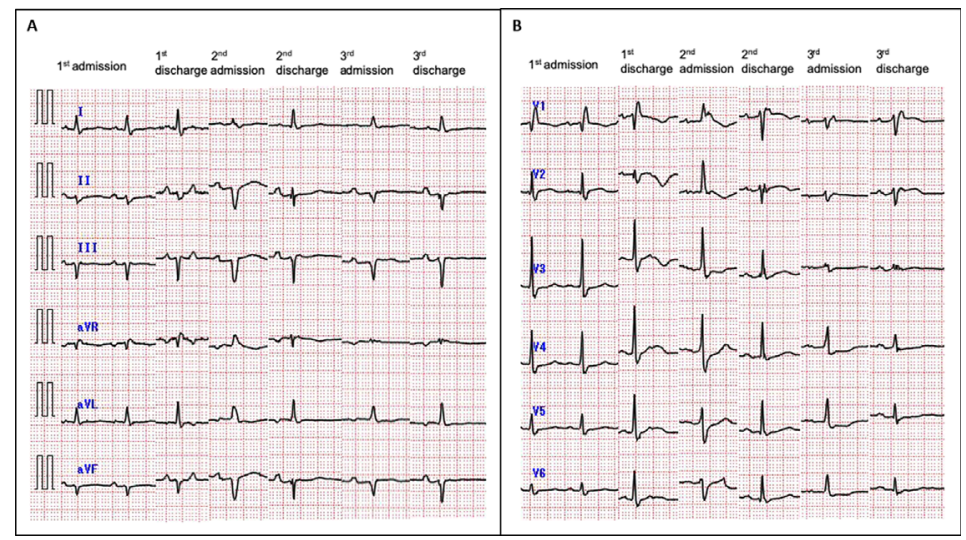

Figure 2. The electrocardiograms recorded at each admission and discharge.
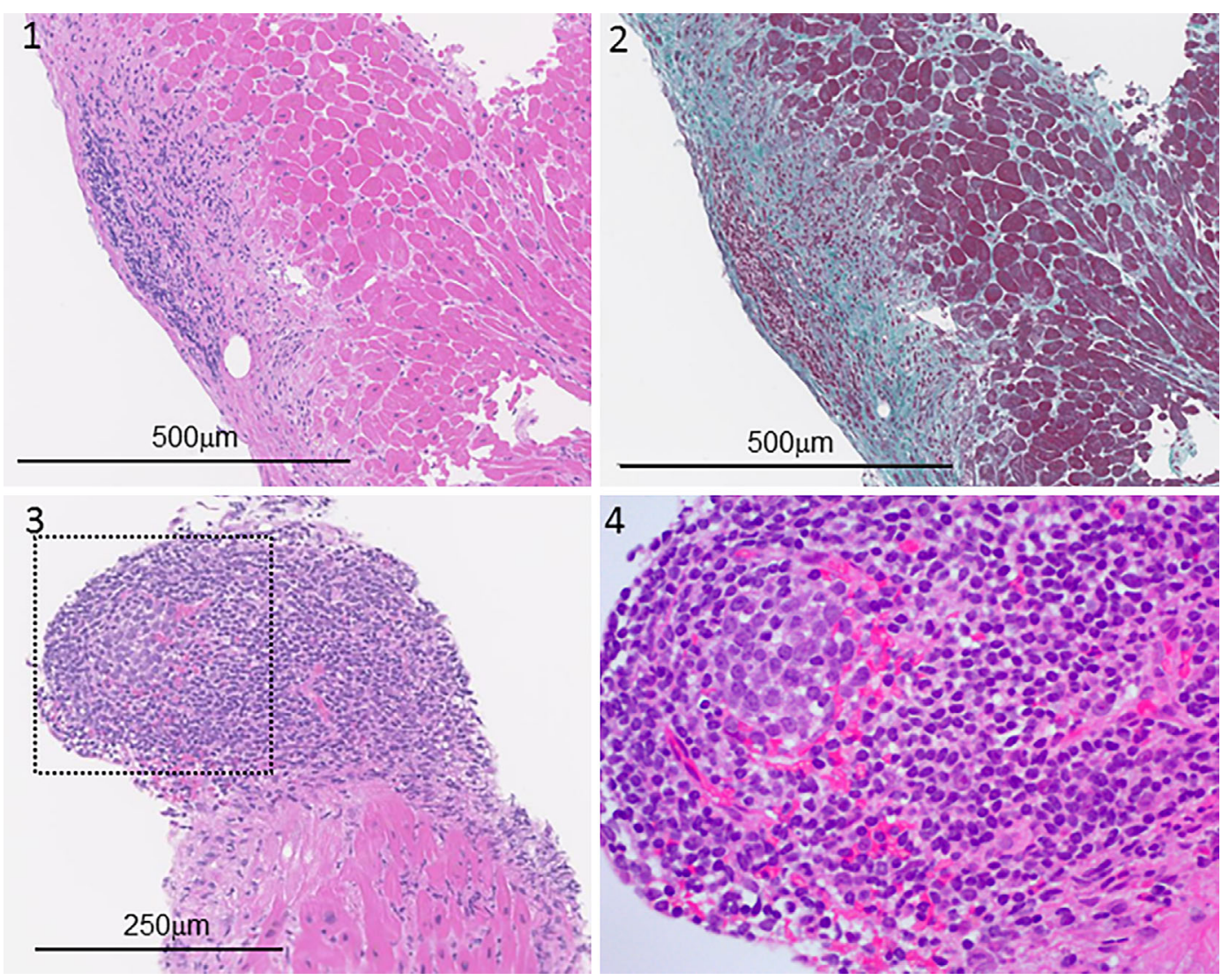

Figure 3. The findings of pathological specimens were compatible with autoimmune myocarditis. A: Inflammatory cells had infiltrated extensively. B: Myocardial fibrosis was occasionally found by Masson trichrome stain. C, D: Inflammatory cells formed a lymphoid follicle that indicated the persistence of chronic inflammation. $D$ is an enlarged image of the square-dashed area of $C$.

lesions, and computed tomography showed no enlargement of the lymph nodes or serologic findings suggestive of sarcoidosis.

Inflammation is the consequence of an immunological response to infection, autoimmunity, cancer, and injury. Appropriate control of inflammation ensures competent host immunity and is governed by cellular communication. However, inappropriate control, such as in autoimmunity, results in sustained immune responses causing chronic inflamma- tion. There is a phenomenon in which, during chronic inflammation, infiltrating immune cells can form highly organized aggregates of lymphoid cells that resemble secondary lymphoid organs (8). These ectopic lymphoid follicles are 'induced' in response to an inflammatory insult within target tissues. Ectopic lymphoid follicles are associated with various autoimmune and chronic inflammatory diseases, including rheumatoid arthritis (9), Sjögren's syndrome (10), and multiple sclerosis (11). These pathological findings indi- 
cate that lymphocytes have recognized endogenous antigens presented to the invaded organs as a result of a compromised immune tolerance and have become persistently activated.

Immunosuppressive therapy is effective against giant-cell myocarditis, cardiac sarcoidosis, and eosinophilic myocarditis (12) but is conversely ineffective against myocarditis due to a persistent viral infection according to previous largescale studies (13). In our case, immunosuppressive therapy was effective all three times, but myocardial biopsy specimens showed no evidence of giant-cell myocarditis, cardiac sarcoidosis, or eosinophilic myocarditis, instead showing lymphoid follicle formation.

Trachtenberg et al. (5) stated that causes of myocarditis could be classified into three groups: autoimmunity, toxic, and infection. Given the pathological findings showing persistent activation of acquired immunity in the myocardium and clinical features, wherein immunosuppressive therapy was remarkably effective, we ultimately diagnosed this case as autoimmune myocarditis. These histological findings were proof of acquired immunity, specifically humoral immunity, that had been activated by an auto-antigen in the myocardium. Such specific findings are expected to help elucidate the etiology of myocarditis.

The authors confirm that written consent for the submission and publication of this case report, including images and associated text, has been obtained from the patient in line with COPE guidance.

The authors state that they have no Conflict of Interest (COI).

\section{References}

1. Sagar S, Liu PP, Cooper LT Jr. Myocarditis. Lancet 379: 738-747, 2012.
2. Feldman AM, McNamara D. Myocarditis. N Engl J Med 343: 1388-1398, 2000.

3. Johnson DB, Balko JM, Compton ML, et al. Fulminant myocarditis with combination immune checkpoint blockade. N Engl J Med 375: 1749-1755, 2016.

4. Cooper LT Jr, Berry GJ, Shabetai R. Idiopathic giant-cell myocarditis-natural history and treatment. Multicenter giant cell myocarditis study group investigators. N Engl J Med 336: 18601866, 1997.

5. Trachtenberg BH, Hare JM. Inflammatory cardiomyopathic syndromes. Circ Res 121: 803-818, 2017.

6. Aretz HT, Billingham ME, Edwards WD, et al. Myocarditis. A histopathologic definition and classification. Am J Cardiovasc Pathol 1: 3-14, 1987.

7. Takehana $H$, Inomata $T$, Kuwao $S$, et al. Recurrent fulminant viral myocarditis with a short clinical course. Circ J 67: 646-648, 2003.

8. Jones GW, Jones SA. Ectopic lymphoid follicles: inducible centres for generating antigen-specific immune responses within tissues. Immunology 147: 141-151, 2016.

9. Manzo A, Bombardieri M, Humby F, Pitzalis C. Secondary and ectopic lymphoid tissue responses in rheumatoid arthritis: from inflammation to autoimmunity and tissue damage/remodeling. Immunol Rev 233: 267-285, 2010.

10. Stott DI, Hiepe F, Hummel M, Steinhauser G, Berek C. Antigendriven clonal proliferation of $\mathrm{b}$ cells within the target tissue of an autoimmune disease. The salivary glands of patients with Sjögren's syndrome. J Clin Invest 102: 938-946, 1998.

11. Magliozzi R, Howell O, Vora A, et al. Meningeal b-cell follicles in secondary progressive multiple sclerosis associate with early onset of disease and severe cortical pathology. Brain 130: 10891104, 2007.

12. Mason JW, O'Connell JB, Herskowitz A, et al. A clinical trial of immunosuppressive therapy for myocarditis. The myocarditis treatment trial investigators. N Engl J Med 333: 269-275, 1995.

13. Mason JW, O'Connell JB, Herskowitz A, et al. A clinical trial of immunosuppressive therapy for myocarditis. The myocarditis treatment trial investigators. N Engl J Med 333: 269-275, 1995.

The Internal Medicine is an Open Access journal distributed under the Creative Commons Attribution-NonCommercial-NoDerivatives 4.0 International License. To view the details of this license, please visit (https://creativecommons.org/licenses/ by-nc-nd/4.0/).

(C) 2020 The Japanese Society of Internal Medicine Intern Med 59: 3045-3049, 2020 